OPEN ACCESS

Edited and reviewed by: Bjorn Johansson,

Karolinska Institutet (KI), Sweden

*Correspondence:

Bettina S. Husebo

Bettina.Husebo@uib.no

Specialty section: This article was submitted to

Neuropharmacology,

a section of the journal

Frontiers in Pharmacology

Received: 07 February 2020

Accepted: 24 February 2020

Published: 06 March 2020

Citation:

Husebo BS, Heintz HL, Berge LI, Owoyemi P, Rahman AT and Vahia IV

(2020) Corrigendum: Sensing Technology to Monitor Behavioral and

Psychological Symptoms and to Assess Treatment Response in People With Dementia. A Systematic Review.

Front. Pharmacol. 11:254. doi: 10.3389/fphar.2020.00254

\section{Corrigendum: Sensing Technology to Monitor Behavioral and Psychological Symptoms and to Assess Treatment Response in People With Dementia. A Systematic Review}

\author{
Bettina S. Husebo ${ }^{1,2 *}$, Hannah L. Heintz ${ }^{3}$, Line I. Berge ${ }^{1,4}$, Praise Owoyemi ${ }^{3}$, \\ Aniqa T. Rahman ${ }^{3}$ and Ipsit V. Vahia ${ }^{3,5}$ \\ ${ }^{1}$ Department of Global Public Health and Primary Care, Centre for Elderly and Nursing Home Medicine, University of Bergen, \\ Bergen, Norway, ${ }^{2}$ Department of Nursing Home Medicine, Municipality of Bergen, Bergen, Norway, ${ }^{3}$ Division of Geriatric \\ Psychiatry, McLean Hospital, Belmont, MA, United States, ${ }^{4}$ NKS Olaviken Gerontopsychiatric Hospital, Bergen, Norway, \\ ${ }^{5}$ Department of Psychiatry, Harvard Medical School, Boston, MA, United States
}

Keywords: dementia, sensoring, monitoring, behavior, therapy

\section{A Corrigendum on}

Sensing Technology to Monitor Behavioral and Psychological Symptoms and to Assess Treatment Response in People With Dementia. A Systematic Review by Husebo, B. S., Heintz, H. L., Berge, L. I., Owoyemi, P., Rahman, A. T., and Vahia, I. V. (2020). Front. Pharmacol. 10:1699. doi: 10.3389/fphar.2019.01699

In the original article, there was an error in the title. It was published as "Sensing Technology to Facilitate Behavioral and Psychological Symptoms and to Monitor Treatment Response in People With Dementia. A Systematic Review."

The correct title should be "Sensing Technology to Monitor Behavioral and Psychological Symptoms and to Assess Treatment Response in People With Dementia. A Systematic Review."

The authors apologize for this error and state that this does not change the scientific conclusions of the article in any way. The original article has been updated.

Copyright $\odot 2020$ Husebo, Heintz, Berge, Owoyemi, Rahman and Vahia. This is an open-access article distributed under the terms of the Creative Commons Attribution License (CC BY). The use, distribution or reproduction in other forums is permitted, provided the original author(s) and the copyright owner(s) are credited and that the original publication in this journal is cited, in accordance with accepted academic practice. No use, distribution or reproduction is permitted which does not comply with these terms. 